\title{
The Application of Digital Media in Display Design
}

\author{
Jun Zhou \\ Sichuan University of Arts and Sciences, Dazhou Sichuan, 635000, China
}

Key words.Digital media technology, Display design, Aesthetic characteristics, Application.

\begin{abstract}
In recent years, with the continuous development and progress of economy and information technology in our society,digital media technology, in the development process of the whole society, plays an increasingly important role. It has an important effect on people's daily life and consumption patterns, but also to a certain extent injects some new vigor and vitalityfor the development of our country in all walks of life. Based on this, this paper introduces the development of China's digital media technology at present, and discusses how to apply the digital media technology in display design.
\end{abstract}

\section{Introduction}

With the rapid development of information technology and digital media technology in China, display design has also madethe unprecedented development and progress. Display design, as a new discipline, has a certain relationship with other disciplines. At the same time, display design has been widely used in many areas in our country. Although display design in our country started late, and its development speed is relatively slow, however, display design isin the process of continuous development all the time, and has continuous improvement and innovation.

\section{Emergence and development of digital media technology}

As early as in the traditional display design,the digital technologyemerged. With the continuous development and the wide application of computer technology, the digital technology has converted from pure theory to reality. At the same time, it is also the continuous use and progressof computer science and technology that makes the traditional research methods largely improved, to promote display design also developed. As a representative of computer technology, digital media technology plays an important role in the whole design process. It is because the extensive application of digital media technology in display design, vigor and vitality of the display design are motivated to the maximum extent.

In addition, with the continuous development of science and technology in China, digital media technology has also been changed to a certain degree.Display design fullyuses design tools of computer technology, which greatly shortens design time of each item. Of course, the extensive application of display technology also, to a certain extent, promotes the development and progress of high technology ${ }^{[1]}$.

\section{Existing problems of digital media technology in the development}

It is imperative to widely apply digital media technology in display design. Especially in developed countries, this trend is more obvious. As China's digital media technology started late, andin the development process, there are some problems and deficiencies, in recent years, many experts and scholars have attached great importance to problems in the development of digital media technology. The following briefly analyzesproblems and deficienciesin the actual development process of digital media technology. 


\section{Some artists seek quick success}

The modern society is at the stage of the rapid development of information technology, but there are some artists, in order to better meet the needs of their own interests, often apply it even if they donot understandrelated knowledge of new technology.Because of this "seek-quick-success" attitude, although to a certain extent, these new technologies can help them to obtain short-term interest, but from the long-term development perspective, these artists will become lost with the support and help of digital technology, and the problem of "hot technology and cold art" emerges.

\section{Artists'knowledge reserve is defective}

With the wide application of digital technology and network technology in all walks of life, the ability of some artists in the actual creation process is becoming gradually degraded. It is precisely because of the gradual loss of their perception and knowledge reserve that leads to the lack of expressive force and vividness in their creative works, thus becoming empty and pale. The reason for this problem is that they are too dependent on digital media technologyin the process of actual creation. In addition, their relatively scarce general knowledge reserve and the utilitarian attitude, finally result in that the initial meaning of digital technology changes gradually.

Therefore, many artists have quite abundant knowledge, but they don't reasonablyuse digital media technology, resulting in their creation gets in the bottleneck period. In addition, some artists are too dependent on digital media technology, therefore,they do not have the attempt to make further progress in the actual creation process, and eventually they get lost ${ }^{[2]}$.

\section{How to well apply digital media technology in display design}

The design effect of modern media technology largely depends on the use of high and new technology. Therefore, a considerable number of artists, in order to show a more intense artistic impact in their works, often use the digital media technology. Beyond doubt, digital media technology has played an important role in the development of display design. Digital media technology has become an inevitable trend in the development of the whole society. A lot of scholars and experts have deeply studiedon how tomore fully apply digital media technology in display design.

\section{More fully apply digital media technology in display design}

The display design in our country has nearly 150 years of development history, and the social form and the development of science and technology play a decisive role in the whole development of display design. First of all, for the effect of the social form on display design, qualitative change of display design is mainly caused by the influence and effect of social form changes. Secondly, from the perspective of science and technology, the continuous development of science and technology in our country, to a certain extent, has played a catalytic role on the development of display design. As an important form of mass information communication, display design becomes more and more important in the development of the whole society. Since we entered the information society, display design is becoming more and more significant in the dissemination of public information. To some extent, digital media art is not only one of the art forms of modern media, but also fully reflects the advanceddevelopment of science and technology in our country. It is because of the gradual application of digital media technologyin display design, modern social information dissemination is more rapid and efficient. Therefore, wide application of digital media technology in the field of display design is not only the actual needs of the development of contemporary society, but also the full embodiment of social progress in china.

\section{Digital media technology brings new change and vitality for display design}

To a certain extent, it is because of gradual application of digital media technology in display design that the development of display design has a new situation. With the development of science and 
technology in China and the emergence and development of new media technologies, in display design, digital media technology is more and more widely applied, which contributes the gradual change of display design from the previous static, passive, single-media and silent state to dynamic, interactive, multimedia and voiced state. Therefore, digital media technology is more and more widely used in display design, which, to a certain extent, injects new vitality and change into the development of the entire displaydesign. The following is a brief analysis and description on the new vitality and change brought by the digital media technology.

First, it is precisely because of wide application of digital media technology in display design that the digital media technology gradually has new changes and vitalityin terms of the space show. In display design, the application of digital media technology, not onlygradually breaks the traditional displayspace form and thinking, but also provides more developmentroom for the new display design. In this aspect, the holographic art and 4D digital art are especially obvious.Second, the two-dimensional display, to a certain extent, has also been affected by the digital media technology. The two-dimensional display is gradually changed from static to dynamic. The two-dimensional display in the traditional design is presented in a static form no matter the text or images, mainly in the form of computer printing, computer printing and computer scribing etc. But with the wide application of digital media technology in two-dimensional display, two-dimensional display forms gradually become digital image and projection show, etc. In addition, it is also because of the extensive application of digital media technologyin two-dimensional display, the original static graphics and textsare replaced by dynamic media, and then the animation, film and video appear. Two-dimensional display will eventually present more information to the public in the most vivid form.Third, the experience-orienteddisplay, to a certain extent, is also affected by digital media technology. Because the experience-orienteddisplay fully uses digital media technology, the traditional display art, only able to be watched, is gradually changed to the experience-oriented display. Visitors can not only understand the works through the vision, but also better control and participate in the works by auditory and other sensory systems, which finally promotes the better satisfaction of participation need and psychological need of self realizationof people, and alsobetter achievesthe ultimate goal of displaying information.Fourth, network display is affected by digital media technology to a certain extent. With the continuous development and prosperity of China's economy, people's daily lives are more and more dependent on the network technology. The network display more and more widely uses digital media technology, and it can not only help people better communicate and exchangeacross space and time barriers, but also allow them to enjoy excellent worksanytime and anywhere.

\section{Digital media technology injects new artistic characteristics into display design}

As one of the important products in the development of modern science and technology, digital media technology has integrated modern science and technology as well as modern multimedia technology. It is also because display design more and more widely uses digital media technology thatgradually display design has different artistic characteristics from some other designs, so as to promote the development of display design to a great extent. The following is a detailed description of the new artistic characteristics of display design brought by the digital media technology.

First, one of the most important characteristics of digital media technology is interactivity, and the most important expression form of digital media technology is the participation of people. Therefore, wider application of digital media technologyin display design not only breaks the time and place limit of traditional works display, but also helps people more actively participate in interactive sessions throughout the works display according to their interests.Through communication and interaction on the Internet, people can put forward his own unique insights and comments on display works, which ultimately promotes people's aesthetic needs to be better satisfied. Therefore, the network technology provides more convenience for people's daily life to a certain extent, but also provides a greater development space for people's artistic appreciation and creation.Second, digital media technology brings the virtual artistic characteristics for display design. As is known to all, all 
things are presented in a virtual way to the eyes of people. Therefore, it is because digital media technology endowsthe virtual artistic characteristics to display design that the time and space limit in the traditional display design is gradually broken down.Third, digital media technology adds the comprehensive artistic characteristics for display design. This is mainly reflected in the people's sense multiplicity and the expression diversity. Addition of the comprehensive artistic characteristicswill not only break the traditional single visual form and artistic form in a timely manner, but also increase the performance and appeal force of display works.Fourth, popularization of digital media technology gives display designbusiness and entertaining characteristics, etc.

\section{Digital media technology gradually changes the way of information transmission}

In the modern society, we are familiar with the multimedia technology. However, if the digital media technology can be more fully applied in display design, display design can have unexpected results. If the digital media technology can be better applied in display design, video and music and other effects, to a large extent, can enhance the performance and appeal force of display works.

Digital media technology has been able to provide a better visual experience for people's daily life, which also relies on the modern display design and advanced science and technology. First, there is a relationship between digital media technology and display design. The reasonable application of digital media technology in display design changes and perfects the traditional way of information transmission. It has gradually changednot only the information transmission form, but also, to some extent, the transmissibility.Second, the reasonable use of digital media technology promotes display design gradually to enter into a new stage of development, not only gradually breaking the traditional form of the carrier, but also realizing the dynamic and virtualization of information transmission.The perfect combination of design and content can not be separated from the virtual imaging art and the good creative atmosphere. Of course, reasonable application of computer equipment in display design has not only opened up a broader development space for the development of the computer, but also to a certain extent, changed the way people communicate and exchange. Generally speaking, the application of digital media technology in modern display design is mainly to make full use of hardware equipment and software technology. Of course, strong technology and innovative art originalityalso play an alternative role in the art creation ${ }^{[3]}$.

\section{Conclusions}

All in all, the development of art is endless. Only the reasonable use of the advanced new technology can inject more new vitality and charm in art works. At the same time, only more perfect application of digital media technology can further enhance appeal force and influence of works.

\section{References}

[1] Qu Yong. Application and Research of Digital Media in Display design. Public Literature and Art, 2014,04:97.

[2] Ding Shixiong, Li Zhuoran. Analysis on the Application of Digital Media Art in Display Design. Modern Decoration (Theory), 2013,10:115-116.

[3] Wei Jie. Application of Digital Media Art in Display Design. Art Technology, 2013,09:90. 